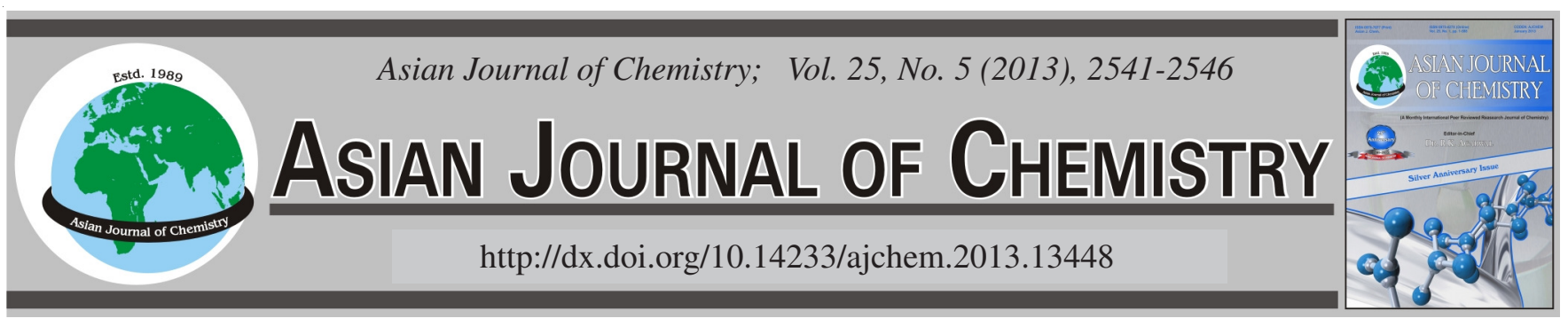

\title{
Synthesis of Vinylphenyl Oligomeric Silsesquioxane Based on MQ Silicone Resin
}

\author{
Ru Li ${ }^{1,2,3}$, BaOtan Zhang $^{3}$, Yongling Sun ${ }^{4}$, B AILING Lid $^{1,3, *}$ and Gongying WANG ${ }^{1,3}$
}

\author{
${ }^{1}$ Chengdu Institute of Organic Chemistry, Chinese Academy of Sciences, Chengdu 610041, P.R. China \\ ${ }^{2}$ Graduate University of Chinese Academy of Sciences, Beijing 100049, P.R. China \\ ${ }^{3}$ Changzhou Key Laboratory of Novel Lighting Source Materials and Technology, Changzhou Institute of Chemistry, Changzhou 213164, P.R. China \\ ${ }^{4}$ School of Materials Science and Engineering, Changzhou University, Changzhou 213164, P.R. China
}

*Corresponding author: Fax:+86 28 85260436; Tel: +86 28 85260436; E-mail: blliuchem@ hotmail.com

(Received: 14 January 2012;

Accepted: 12 November 2012)

AJC-12397

\begin{abstract}
A novel vinylphenyl oligomeric silsesquioxane (VPOSS) based on MQ silicone resins were synthesised by cohydrolysis and polycondensation of phenyltriethyloxysilane, tetraethyloxysilane, 1,4-divinyltetramethyldisiloxane and hexamethyldisiloxane. The structure, morphology and properties of the developed copolymers were investigated by FTIR, DSC, XRD, ${ }^{1} \mathrm{H}$ and ${ }^{29} \mathrm{Si}$ NMR, GPC, TGA and SEM. The heat of fusion $\left(\Delta \mathrm{H}_{\mathrm{f}}\right)$ measured for crystal melting was $21.27 \mathrm{~J} / \mathrm{g}$ for VPOSS V. The results indicated that the cage and/or ladder structure and the decreasing content of $\mathrm{M}$ unit $(\mathrm{mol} \%)$ in copolymers enhanced the thermal properties of the VPOSSs. The scanning electron microscopy images showed curved surface and lamellar fracture of VPOSS, which can be specialties of potential materials for connectivity and supporter of catalyst. Also, the most important applications are that multifunctional VPOSSs can be used as potential moieties for temperature resistance pressure sensitive adhensive and high performance liquid silicone rubber as light emitting diode encapsulation materials.
\end{abstract}

Key Words: Silsesquioxane, MQ resin, Polysiloxane, Multifunctional.

\section{INTRODUCTION}

Oligomeric silsesquioxane (OSS), $\left[\mathrm{RSiO}_{1.5}\right]_{\mathrm{n}}(\mathrm{n}=4,6,8$, $10,12, \ldots)$, with a distinctive nanocage structure consisting of an inorganic core of silicon and oxygen atoms and an outer shell of organic functional groups is one of the most promising nanomaterials for aerospace, electronics, macromers, catalysts, surfaces, biomaterials, nanocomposites and medical applications ${ }^{1-6}$. And these applications were all based on the difference of organic R groups, such as aryl, alkyl, hydrogen, vinyl and other related organic/inorganoic groups. As its various functions, phenyl-oligomeric silsesquioxane have received numerous interests in the last few decades ${ }^{3-5,7}$.

Phenyl-oligomeric silsesquioxane was first reported by Barry et $a l^{8}$. And it was used to be synthesized from the hydrolysis and polycondensation of $\mathrm{PhSiX}_{3}$, where the $\mathrm{X}$ groups being $\mathrm{Cl}, \mathrm{Br}$ or $\mathrm{OR}$ units ${ }^{3-5,7,9}$. Phenyl-oligomeric silsesquioxane can be modified through various organic or inorganic functional reactions, including acylation, nitration, diazotization and halogenations ${ }^{3}$.

Moreover, MQ resin, a three-dimensional silicone polymer with low molecular weight, consisted of mono-functional siloxane $(\mathrm{M})$ and tetra-functional siloxane $(\mathrm{Q})^{10,11}$, have also absorbed great attention because of its excellent exhibition when it serves as the fillers of temperature resistance pressure sensitive adhensive (PSA) ${ }^{12}$ and liquid silicone rubber (LSR) applied for light emitting diode (LED) encapsulant ${ }^{13}$. The so called MQ silicone resin was first synthesized in 1950 ' $\mathrm{s}^{14}$ and was studied systematically by Huang and his co-workers through cohydrolysis and polycondensation approach ${ }^{10}$. In addition, MQ resin also used to be an anchoring backbone for mesogens opens up a way to develop a new group of readily available hybrid liquid crystalline materials ${ }^{15}$.

However, above discussed oligomeric silsesquioxanes were always directly prepared with mono kinds of functional, the approach to generate multifunctional oligomeric silsesquioxane derivatives depends on the functionalization of precursor oligomeric silsesquioxane through hydrosilylation of alkenes or alkynes with $\mathrm{Si}-\mathrm{H}$ group contained oligomeric silsesquioxane ${ }^{3,16-18}$.

In this paper, we tentatively attempt to directly synthesize a novel kind of multifunctional vinylphenyl oligomeric silsesquioxane (VPOSS) by the cohydrolysis and polycondensation approach. Thereafter, we discussed the structure, thermal properties and morphologies of VPOSS series, which can be specialties of potential materials for connectivity and supporter 
of catalyst. The multifunctional VPOSS can also be potential moieties for temperature resistance PSA and fillers for high performance LED encapsulation LSR.

\section{EXPERIMENTAL}

Phenyltriethoxysilane (PTES, $98 \%$ ) was purchased from J \& K Scientific Ltd. (China). Hexamethyldisiloxane (MM, $99 \%$ ) and 1,4-divinyltetramethyldisiloxane $\left({ }^{\mathrm{Vi}} \mathrm{MM}^{\mathrm{Vi}}, 99 \%\right)$ were purchased from Zhejiang Sanmen Qianhong Industries Co., Ltd. (Zhejiang, China). Tetraethyloxysilane (TEOS, $99 \%$ ) was purchased from Shanghai Lingfeng Chemical Regent Co. Ltd. (Shanghai, China). All of the chemicals were used as received.

Synthesis of VPOSS: VPOSS were prepared by cohydrolysis and polycondensation. The given amounts of monomers (Table-1) were added in a flask equipped with a stirrer and reflux condenser. The $\mathrm{HCl}$ solution $(1 \mathrm{~mol} / \mathrm{L}$ ) was used to adjust the $\mathrm{pH}$ of the reaction system to 1-2 and then the reaction temperature was gradually raised to $75{ }^{\circ} \mathrm{C}$ for conducting the cohydrolysis procedure in $c a .2 .5 \mathrm{~h}$. Whereafter, the toluene, as azeotrope former, was added to the system to remove the low-boiling ethanol-water compounds. The $\mathrm{pH}$ of reaction system was adjusted to $10-11$ with $\mathrm{NaOH}$ for carrying out the postcondensation distillation, which was in alkaline media at $80^{\circ} \mathrm{C}$ for $c a .1 .5 \mathrm{~h}$ until no distillate was observed in the distilling head and the toluene-ethanol-water azeotrope was removed from the system simultaneously. The product was cooled to room temperature before analysis.

Purification of VPOSS: To purify the product, deionized water was used to extract ethanol and wash the organic layer to $\mathrm{pH}$ 6-7. The upper organic layer was then dried to transparent with anhydrous calcium chloride. After the desiccant was removed by filtration, a solution of VPOSS in toluene with a concentration ca. $50 \%$ (wt \%) was obtained. A viscous liquid/ solid powder was obtained after removing the volatile matters from the solution at $10 \mathrm{mmHg}$ with gradually increasing temperature to $150{ }^{\circ} \mathrm{C}$ and kept for $0.5 \mathrm{~h}$.

Characterization: ${ }^{1} \mathrm{H}$ and ${ }^{29} \mathrm{Si}$ nuclear magnetic resonance (NMR) were used to characterize the structure of VPOSS. ${ }^{1} \mathrm{H}$ NMR spectra were acquired on Bruker Avance III $500 \mathrm{MHz}$ spectrometer using $\mathrm{CDCl}_{3}$ as a solvent, while ${ }^{29} \mathrm{Si}$ NMR were carried out on Bruker Avance DPX-300MHz spectrometer with solvent of $\mathrm{CDCl}_{3}$.

Infrared absorption spectra were collected on a Nicolet PROTÉGÉ 460 Fourier transform infrared (FTIR) instrument. Samples were dissolved in dichloromethane to make a concentration of $10 \%$ (wt \%) and coated on a $\mathrm{KBr}$ lens or ground with $\mathrm{KBr}$ crystal to make $1 \mathrm{wt} \%$ mixtures and pelletized.

Gel permeation chromatography (GPC) analysis of all the samples was carried out on PL-GPC 50 Plus system equipped with a 290-LC pump injection, two $300 \mathrm{~mm} \times 7.5 \mathrm{~mm}$ PLgel MIXED-B and MIXED-C colums and a PL-RI Detector. The operation was performed at $35^{\circ} \mathrm{C}$, using tetrahydrofuran (THF) as the solvent with a flow rate of $1.0 \mathrm{~mL} / \mathrm{min}$. The molecular weight standards are polystyrenes.

The thermal-transitions of the copolymers were determined on TA instruments Q20 differential scanning calorimetry (DSC), which was calibrated from the melting temperature $\left(\mathrm{T}_{\mathrm{m}}\right)$ of indium $\left(156.63^{\circ} \mathrm{C}\right)$. The temperature was increased at a rate of $10^{\circ} \mathrm{C} / \mathrm{min}$ from -80 to $240^{\circ} \mathrm{C}$.

Thermo gravimetric analysis (TGA) measurement was carried out on TA instrument SDT Q600 at a flow rate of 50 $\mathrm{mL} / \mathrm{min}$ in nitrogen or air. The temperature was increased at a rate of $10^{\circ} \mathrm{C} / \mathrm{min}$ from room temperature to $800^{\circ} \mathrm{C}$.

The X-ray diffraction (XRD) analysist of the product was performed on Rigaku D/max 2500 PC powder X-ray diffractometer using $\mathrm{CuK}_{\alpha}(40 \mathrm{KV}$ and $\lambda=0.154 \mathrm{~nm})$ radiation, over the $2 \theta$ range of $2-90^{\circ}$ with a step size of $0.02^{\circ}$ at a scanning speed of $0.2 \% \mathrm{~min}$.

The morphology of samples was observed in a field emission scanning electron microscopy (SEM) instrument (JEOL, JSM-6360LA) under an operating voltage of $15.0 \mathrm{kV}$. Sample powders were sputtercoated with 1-4 nm of Au to reduce charging effects.

\section{RESULTS AND DISCUSSION}

Characterization of VPOSS: Generally, the synthesis of oligomeric silsesquioxane lasted for few days ${ }^{3}$. In present work, we attempted to obtain the expected multifunctional oligomeric silsesquioxane rapidly, therefore the classical cohydrolysis and polycondensation method has been adopted for this purpose. The different molar ratio of feed materials for synthesized VPOSS series were listed in Table-1 and the chemical and thermal analysis were presented in Table- 2 .

FT-IR spectroscopy: FT-IR spectrum of VPOSS IV is shown in Fig. 1. The relatively broad band at $3425 \mathrm{~cm}^{-1}$ is the intermolecular and/or intramolecular hydrogen bonds ( $\mathrm{SiOH}-$ $\mathrm{H})^{19}$. The strong sharp peaks at 1633 and $958 \mathrm{~cm}^{-1}$ are caused by symmetric deformation vibration of $\mathrm{Si}-\mathrm{CH}=\mathrm{CH}_{2}$ associated with $\mathrm{M}(\mathrm{VI})$ grafted onto VPOSS ${ }^{19}$. While the sharp peak at 1255 and $838 \mathrm{~cm}^{-1}$ are confirmed to be the symmetric deformation vibration of $\mathrm{Si}_{-} \mathrm{CH}_{3}$ in VPOSS ${ }^{19}$. In addition, the sharp peaks at 2959, 2853 and $2925 \mathrm{~cm}^{-1}$ are attributed to the stretching vibration of $\mathrm{C}-\mathrm{H}$ group on $-\mathrm{Si}\left(\mathrm{CH}_{3}\right)_{2} \mathrm{CH}=\mathrm{CH}_{2}$ and the peaks at 3008,3051 and $3074 \mathrm{~cm}^{-1}$ are assigned to the stretching vibration of $\mathrm{C}-\mathrm{H}$ group on $\mathrm{Si}_{-}-\mathrm{C}_{6} \mathrm{H}_{5}{ }^{19}$. Furthermore, peaks at 1822,1890 and $1959 \mathrm{~cm}^{-1}$ are associated with the overtone and combination bands of C-H on $\mathrm{Si}_{-} \mathrm{C}_{6} \mathrm{H}_{5}$ deformation vibrations. And, the peaks of 697,738 and $789 \mathrm{~cm}^{-1}$ are formed by ring deformation vibration and $\mathrm{C}-\mathrm{H}$ deformation vibration of ring

TABLE-1

FEED MOLE RATIO FOR SYNTHESIS OF VPOSS SERIES

\begin{tabular}{|c|c|c|c|c|c|c|}
\hline Entry & $\mathrm{MM}(\mathrm{mmol})$ & PTES (mmol) & TEOS (mmol) & ${ }^{\mathrm{Vi}} \mathrm{MM}^{\mathrm{Vi}}(\mathrm{mmol})$ & $\mathrm{R} / \mathrm{Si}$ & Status \\
\hline I & 34.568 & 62.5 & 39.904 & 8.871 & 1.71 & Liquid \\
\hline II & 26.543 & 62.5 & 39.904 & 8.871 & 1.58 & Liquid \\
\hline III & 18.519 & 62.5 & 39.904 & 8.871 & 1.44 & Solid \\
\hline IV & 9.259 & 62.5 & 39.904 & 8.871 & 1.24 & Solid \\
\hline V & 0 & 62.5 & 39.904 & 8.871 & 0.96 & Solid \\
\hline
\end{tabular}


TABLE-2

CHEMICAL AND THERMAL ANALYSIS OF SYNTHESIZED VPOSS SERIES

\begin{tabular}{ccccccccc}
\hline Entry & $\mathrm{R} / \mathrm{Si}$ & $\mathrm{M}_{\mathrm{n}}{ }^{\mathrm{a}}$ & $\mathrm{M}_{\mathrm{w}}{ }^{\mathrm{a}}$ & $\mathrm{M}_{\mathrm{w}} / \mathrm{M}_{\mathrm{n}}{ }^{\mathrm{a}}$ & $\mathrm{T}_{\mathrm{g}}\left({ }^{\circ} \mathrm{C}\right)^{\mathrm{b}}$ & $\mathrm{T}_{\mathrm{m}}\left({ }^{\circ} \mathrm{C}\right)^{\mathrm{b}}$ & $\mathrm{T}_{\mathrm{d} 5 \%}\left({ }^{\circ} \mathrm{C}\right)^{\mathrm{c}}$ \\
\hline I & 1.71 & 1200 & 1500 & 1.21 & -60 & - & - & 180 \\
II & 1.58 & 1300 & 1600 & 1.25 & -33 & - & 228 \\
III & 1.44 & 1500 & 2100 & 1.40 & -7 & - & 233 \\
IV & 1.24 & 1800 & 2600 & 1.48 & 43 & - & 342 \\
V & 0.96 & 2300 & 3600 & 1.57 & - & 30 & 401 \\
\hline${ }^{\mathrm{a}}$ De & & &
\end{tabular}

${ }^{\mathrm{a}}$ Determined by GPC. ${ }^{\mathrm{b}}$ Determined by DSC, $10^{\circ} \mathrm{C} / \mathrm{min}$. ${ }^{\mathrm{c}}$ Determined by TGA in air, $10 \% \mathrm{~min}$.

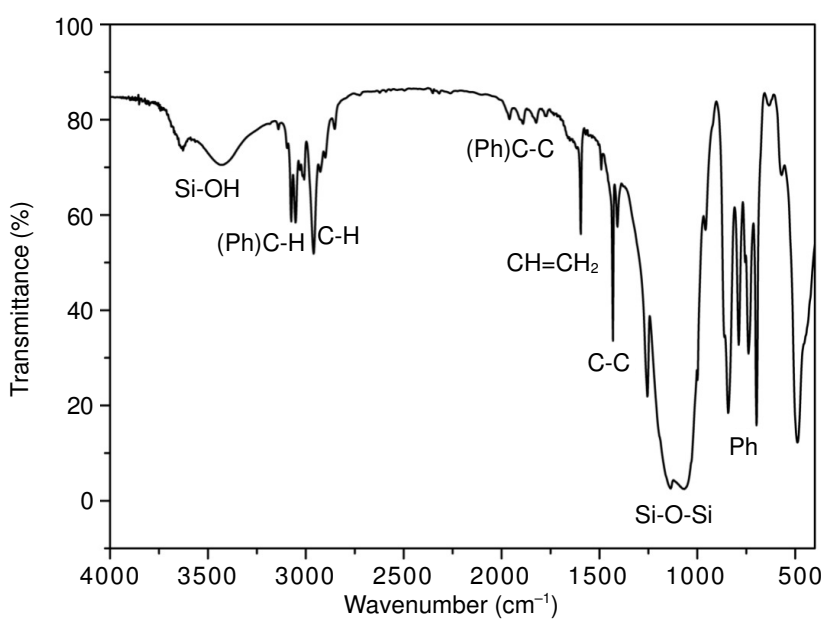

Fig. 1. FT-IR spectra of synthesized VPOSS IV

hydrogens of phenyl group, respectively ${ }^{19}$. Moreover, the sharp peaks at 1595 and $1431 \mathrm{~cm}^{-1}$ are C-C stretching vibration of mono-substituted benzene $\left(\mathrm{Si}-\mathrm{C}_{6} \mathrm{H}_{5}\right)$, which indicates the presence of $\mathrm{Si}-\mathrm{Ph}$ grafted on VPOSS ${ }^{19}$. The classical asymmetric stretching vibration of $\mathrm{Si}-\mathrm{O}-\mathrm{Si}$ is a broad band ${ }^{19}$ at $1200-1000$ $\mathrm{cm}^{-1}$. All these correspond with the results obtained by ${ }^{1} \mathrm{H}$ and ${ }^{29} \mathrm{Si}$ NMR analyses.

In addition, we have known from the FT-IR studies ${ }^{20-23}$, whether the ladder or cage structure, are both possible structure for oligomeric silsesquioxanes. In Fig. 1, the peaks ranging from $1200-1000 \mathrm{~cm}^{-1}$ originate from the stretching vibration of the -Si-O-Si- bond in the horizontal and vertical direction of the polysilsesquioxane backbone, indicating that it is one of the structures of either ladder, cage or random network ${ }^{20,22}$. Furthermore, two absorptions of bimodal shape appear near 1150 and $1050 \mathrm{~cm}^{-1}$ indicate ladder structure of oligomeric silsesquioxane, while one strong absorption peak near 1100 $\mathrm{cm}^{-1}$ shows closed cage structure ${ }^{20,21,24}$ in FT-IR spectra. Also, the strong bimodal shape can be seen clearly in Figs. 1 and 2, implying that VPOSSs processed a larger portion of the laddered structure than other type of structures shown in Scheme-I.

${ }^{1} \mathrm{H}$ and ${ }^{29} \mathrm{Si}$ NMR spectroscopy: The structure of VPOSSs was characterized by ${ }^{1} \mathrm{H}$ and ${ }^{29} \mathrm{Si}$ NMR. A complicated phenyl region at 7-8 ppm with a group peaks is observed in the ${ }^{1} \mathrm{H}$ NMR spectra (Fig. 3). This implies that the copolymers have the random structures ${ }^{19}$. Also, a broad peak detected at 5.3$6.2 \mathrm{ppm}$ are assigned to vinyl group of $-\mathrm{OSi}\left(\mathrm{CH}_{3}\right)_{2} \mathrm{CH}=\mathrm{CH}_{2}$. In addition, for sample III, broad weak peaks observed at 3.74 and $1.77 \mathrm{ppm}$ indicate that some residual unreacted $\mathrm{Si}$ $\mathrm{OCH}_{2} \mathrm{CH}_{3}$ groups still remaine in the copolymers ${ }^{19}$, while weak peak at $2.36 \mathrm{ppm}$ and hump peak at 0.5-1.4 ppm are assigned to the residual $\mathrm{Si}-\mathrm{OH}$ groups (Fig. 3).

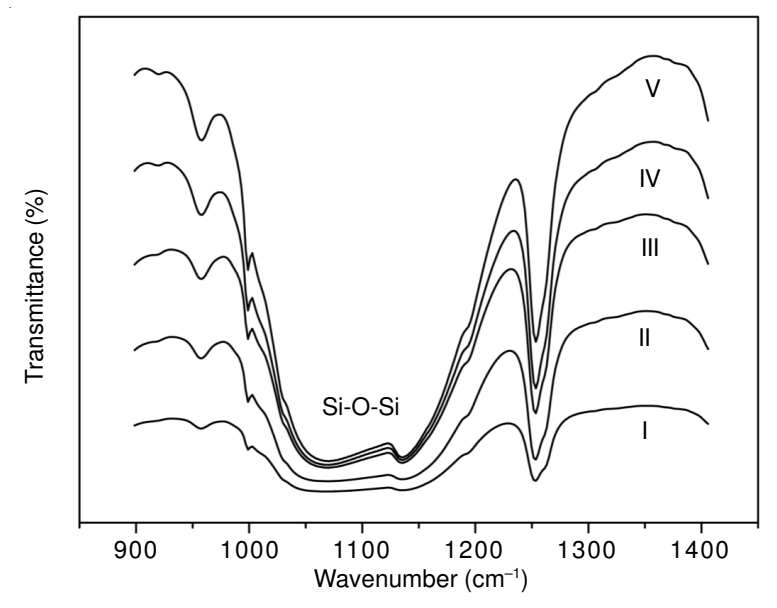

Fig. 2. FT-IR spectra in range of $1400-900 \mathrm{~cm}^{-1}$ for identifing the structure of synthesized VPOSS series

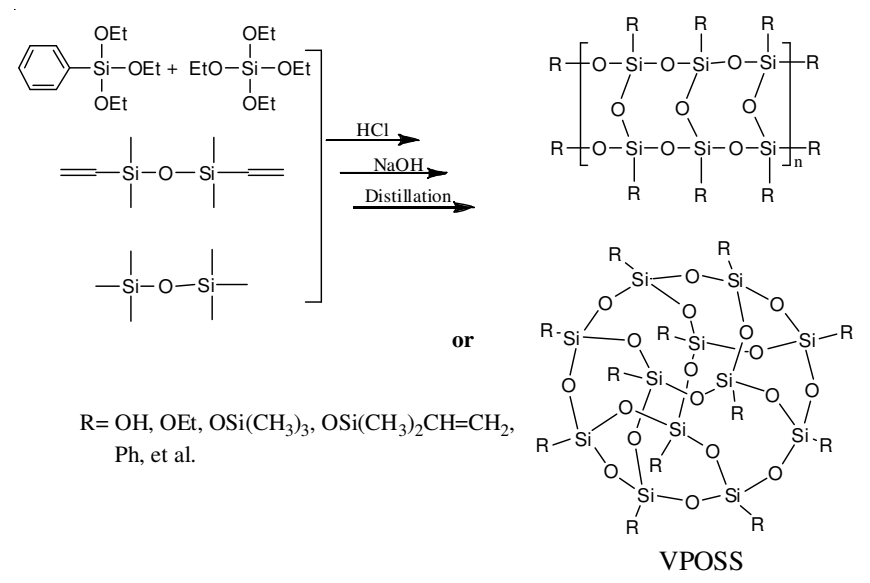

Scheme-I: Synthesis procedure of VPOSS series

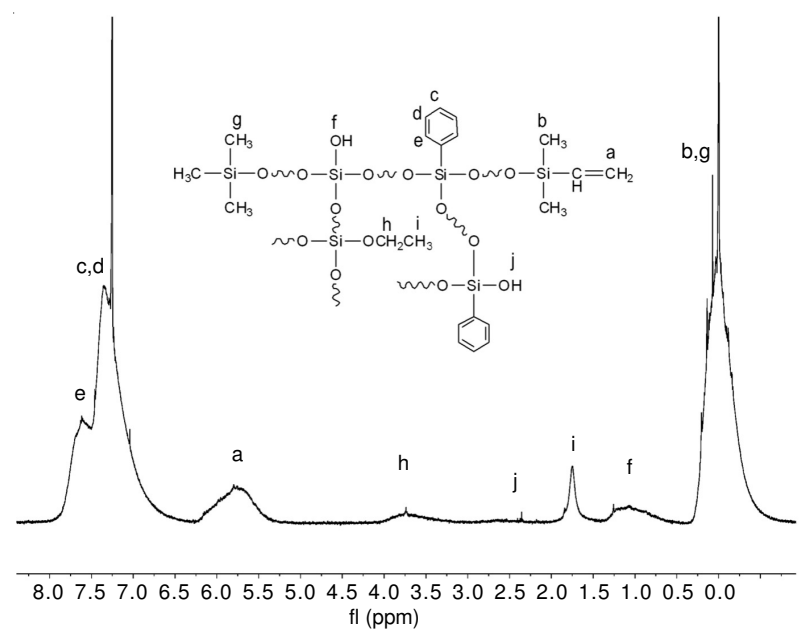

Fig. 3. ${ }^{1} \mathrm{H}$ NMR of synthesized VPOSS IV 
${ }^{29} \mathrm{Si}$ NMR spectroscopy has been considered a useful tool to determine the structure of organosilicon compounds ${ }^{4,19,25}$. As is shown in Fig. 4, four resonances observed in ${ }^{29} \mathrm{Si} \mathrm{NMR}$ spectra can be accounted for $\mathrm{M},{ }^{\mathrm{V}} \mathrm{M}, \mathrm{T}^{\mathrm{Ph}}$ and $\mathrm{Q}$ units, respectively (Figs. 4 and 5) ${ }^{19,26}$. And the chemical shifts of $\mathrm{M},{ }^{\mathrm{V}} \mathrm{M}$, $\mathrm{T}^{\mathrm{Ph}}$ and $\mathrm{Q}$ units are 9.62, -2.64, -80.93 and $-110.24 \mathrm{ppm}$, respectively ${ }^{19}$. The theoretical content $(\mathrm{mol} \%)$ of $-\mathrm{OSi}\left(\mathrm{CH}_{3}\right)_{3}$ is decreasing from I-V (Table-1), fortunately, this trend has been confirmed and seen obviously in Fig. 5, where the area of $\mathrm{M}$ unit region of VPOSS at $9.62 \mathrm{ppm}$ reduces gradually. The broad shoulder of these peaks shows that the structure of copolymers are randomized ${ }^{4,25,27}$.

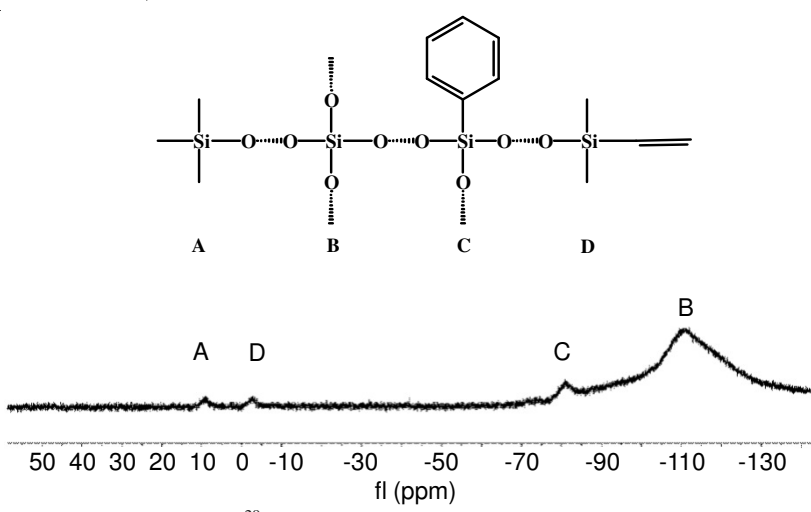

Fig. $4 .{ }^{29} \mathrm{Si}$ NMR of synthesized VPOSS IV

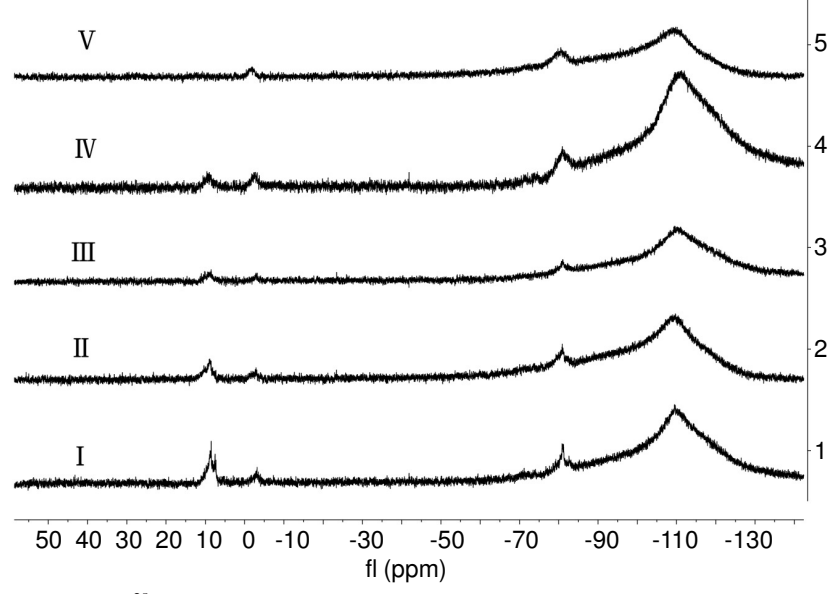

Fig. $5 .{ }^{29} \mathrm{Si}$ NMR comparison of synthesized VPOSS sample series

Thermal properties: The low molecular weight (from $1200-2300 \mathrm{~g} / \mathrm{mol}$ ) of the VPOSSs physically behaved like from high viscosity liquid to solid powder at room temperature. As is shown in Fig. 6 and Table-2, these materials have the $T_{g}$ $\left(-60{ }^{\circ} \mathrm{C}\right.$ to $\left.43^{\circ} \mathrm{C}\right)$ and $\mathrm{T}_{\mathrm{m}}\left(\mathrm{ca} .30^{\circ} \mathrm{C}\right)$. The slightly higher glass transition temperature observed for the VPOSS series is attributed to the decreasing content of M units, which can increase the molecular weight and ladder structure of VPOSS. As discussed above, the ladder structure is also observed in FT-IR spectra (Fig. 2). Moreover, the $\mathrm{T}_{\mathrm{m}}\left(60-265^{\circ} \mathrm{C}\right)$ for oligomeric silsesquioxane phase was detected by DSC. Melting transitions have been observed from oligomeric silsesquioxanes ${ }^{25}$. Samples V with a $\mathrm{T}_{\mathrm{m}}\left(\mathrm{ca} .30^{\circ} \mathrm{C}\right)$ can be accounted to the VPOSS cages or ladders crystal. In addition, the heats of fusion $\left(\Delta \mathrm{H}_{\mathrm{f}}\right)$, the total heat of fusion over the whole melting transition measured

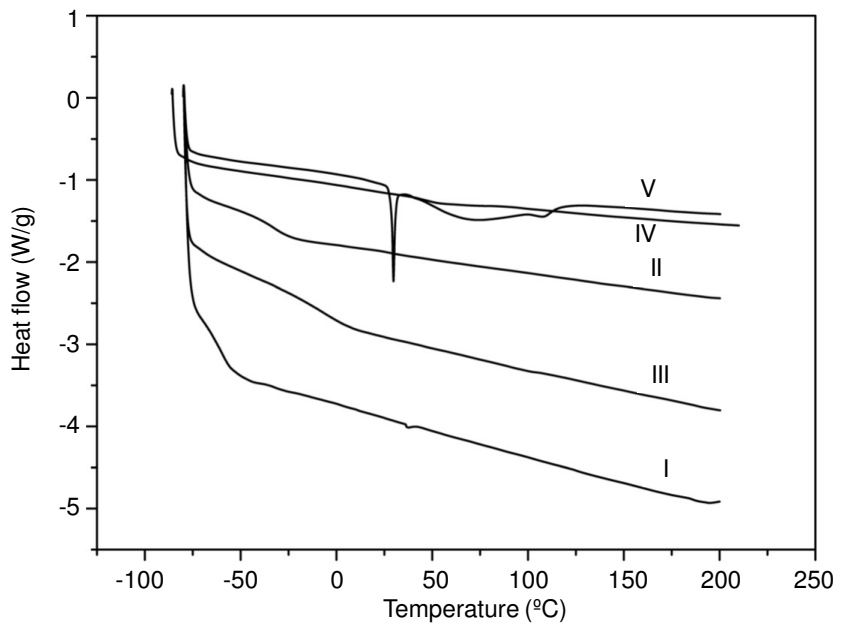

Fig. 6. DSC curves of synthesized VPOSS series, $10^{\circ} \mathrm{C} / \mathrm{min}$

for VPOSS V, was calculated from the sharp and broad peaks in DSC curves shown in Fig. 6. And the $\Delta \mathrm{H}_{\mathrm{f}, \mathrm{V}, \mathrm{VPOSS}}$ is 21.27 $\mathrm{J} / \mathrm{g}$ of VPOSS V, which is close to the reported values ${ }^{4}$.

The temperature for the highest thermal stability of all VPOSSs is $401{ }^{\circ} \mathrm{C}$ with $5 \%$ decomposition in air $\left(\mathrm{T}_{\mathrm{d}}, 5 \%\right.$, air). Thus, the thermal stability is almost the same or better than that of MQ silicone resin ${ }^{28}$ (Fig. 7, Fig. 8 and Table-3). As is shown in Fig. 8, the first step of thermal decomposition at range $200-460^{\circ} \mathrm{C}$ is probably a consequence of decomposition of organic groups, may be resulted from the polycondensation and degradation of $-\mathrm{Si}-\mathrm{CH}=\mathrm{CH}_{2},-\mathrm{Si}-\mathrm{Ph},-\mathrm{Si}-\mathrm{CH}_{3},-\mathrm{Si}-\mathrm{OH}$ or -Si-OEt, while the second step can be accounted for the degradation of the backbone of VPOSS at range $460-700{ }^{\circ} \mathrm{C}$ in nitrogen ${ }^{29-31}$. Hence, significantly increased thermal stability compared with that of MQ silicone resin would be expected if the ladder structure oligomeric silsesquioxane were the core and cross-linker of copolymers ${ }^{20}$. Moreover, the onset temperature increased with the decreasing content of $\mathrm{M}$ unit mol \% in copolymers indicates that the ladder and/or cage structure can surely enhance the thermal stability of VPOSSs ${ }^{20,25}$.

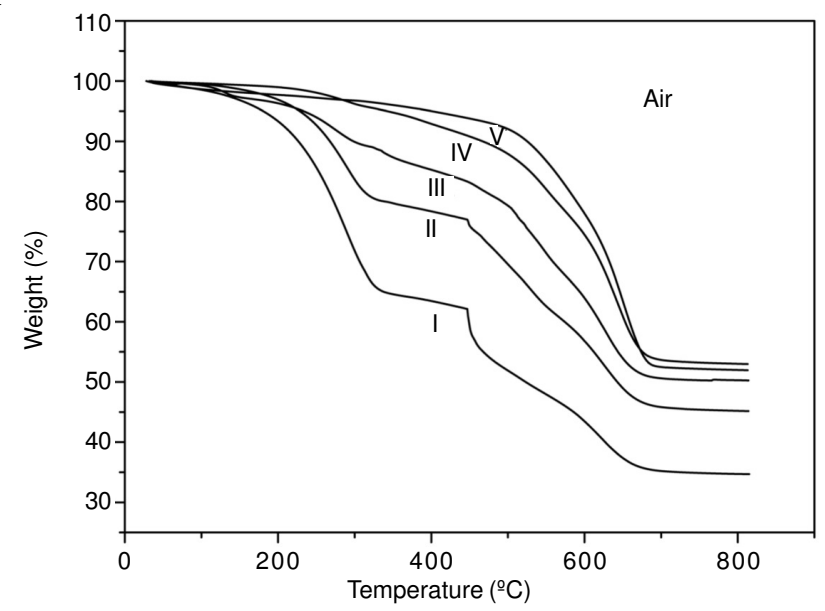

Fig. 7. TGA curves of synthesized VPOSS series in air, $10^{\circ} \mathrm{C} / \mathrm{min}$

X-Ray diffraction: XRD analysis used to investigate the VPOSSs structures will present more detail information. Fig. 9 shows the X-ray diffraction of VPOSS IV and V. 


\begin{tabular}{|c|c|c|c|c|c|c|c|c|}
\hline \multirow{3}{*}{ Entry } & \multicolumn{7}{|c|}{ TABLE-3 } & \\
\hline & \multicolumn{4}{|c|}{ Temperature at weight loss (\%) in air ${ }^{\mathrm{a}}$} & \multicolumn{4}{|c|}{ Temperature at weight loss (\%) in $\mathrm{N}_{2}^{\mathrm{b}}$} \\
\hline & 5 & 10 & 15 & 20 & 5 & 10 & 15 & 20 \\
\hline I & 181 & 226 & 253 & 273 & 181 & 224 & 249 & 267 \\
\hline II & 228 & 268 & 293 & 339 & 226 & 268 & 292 & 311 \\
\hline III & 233 & 299 & 407 & 492 & 258 & 302 & 332 & 361 \\
\hline IV & 319 & 397 & 527 & 564 & 342 & 467 & 529 & 564 \\
\hline V & 401 & 525 & 561 & 590 & 353 & 525 & 572 & 634 \\
\hline
\end{tabular}

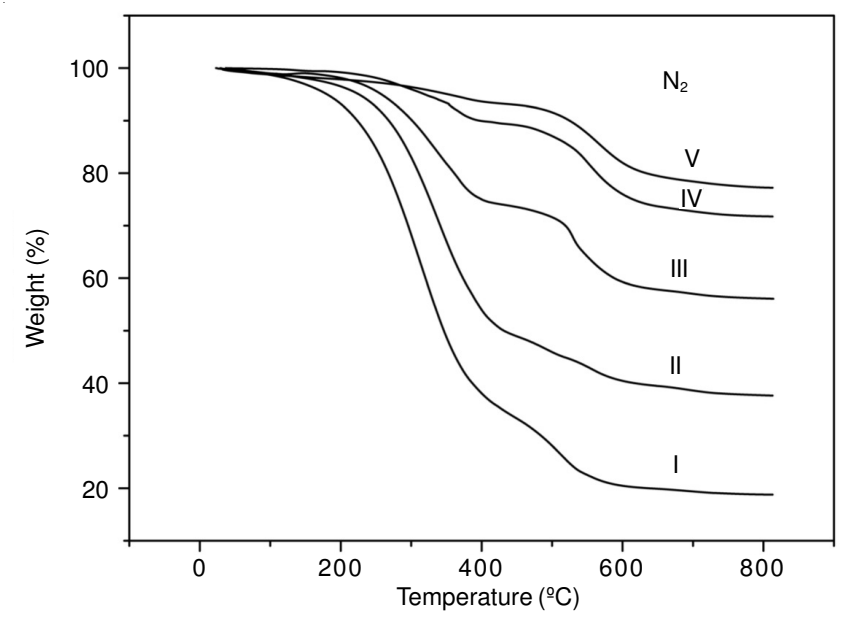

Fig. 8. TGA curves of synthesized VPOSS series in $\mathrm{N}_{2}, 10^{\circ} \mathrm{C} / \mathrm{min}$
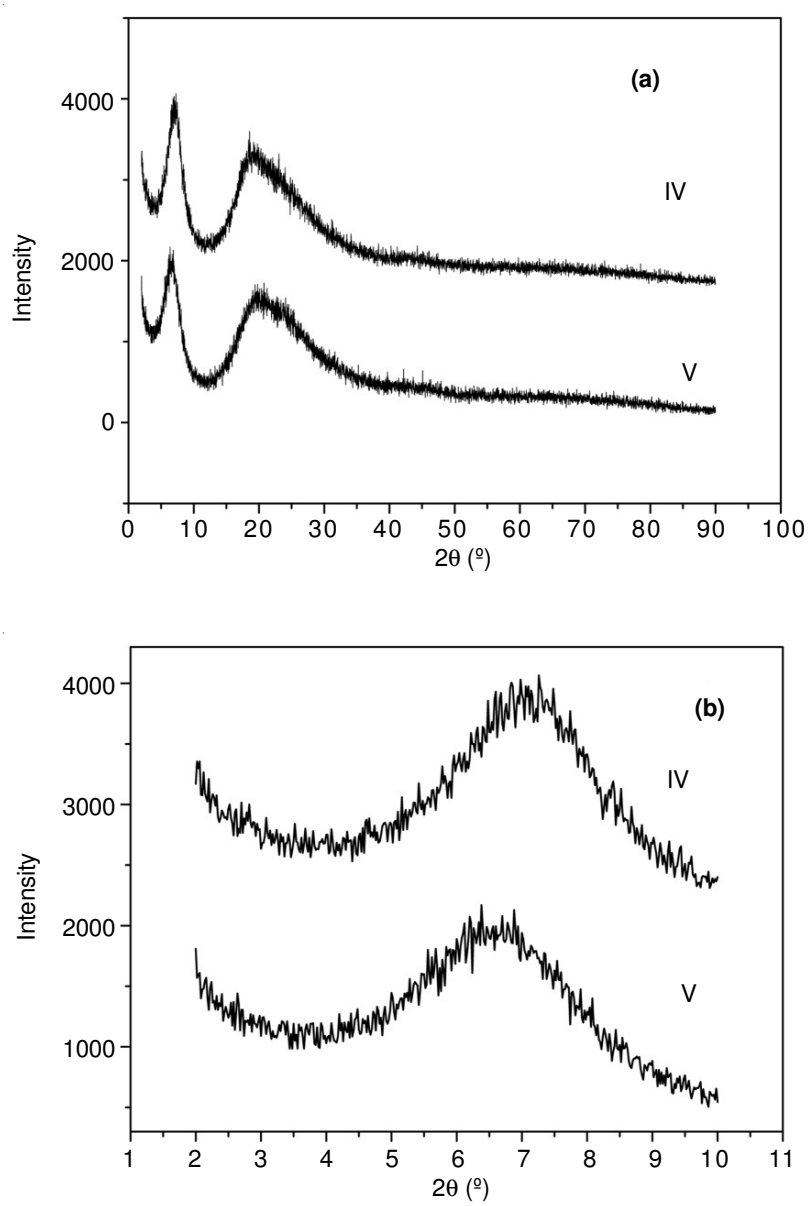

Fig. 9. XRD spectra of synthesized VPOSS IV and V (a) full scale, (b) extended scale
As discussed above, VPOSSs with good thermal properties can tentatively interpret its cage/ladder structure ${ }^{3,24,25}$. The reaction chemistry is presumably identical for each VPOSS, powder XRD shows peaks $2 \theta$ at $6.98^{\circ}, 18.55^{\circ}$ corresponding to a d-spacing of $c a .12 .65$ and $4.77 \AA$ for VPOSS IV, while for VPOSS V is $2 \theta$ at $6.66^{\circ}, 19.88^{\circ}$ corresponding to a d-spacing of ca. 13.26 and $4.46 \AA$, respectively. This result is also in excellent agreement with the predicted ladder width (12.2 $\mathrm{A})$ and ladder thickness (5.1 $⿱$ ), , on the basis of molecular simulation calculations with the simulation software, Alchemy 2000, version $1.0^{32}$.

Scanning electron microscopy: The SEM images in Fig. 10 reveal a gross morphology of VPOSS V. The curved surface and lamellar fracture show the disordered, glassy structure of the VPOSS V materials, which is similar to cage structure POSS morphology reported by Roll ${ }^{3,24}$. It can be the potential materials for connectivity and supporter of catalyst ${ }^{24}$ and the most important property is the potential usage of fillers in LSR as LED encapsulation materials.
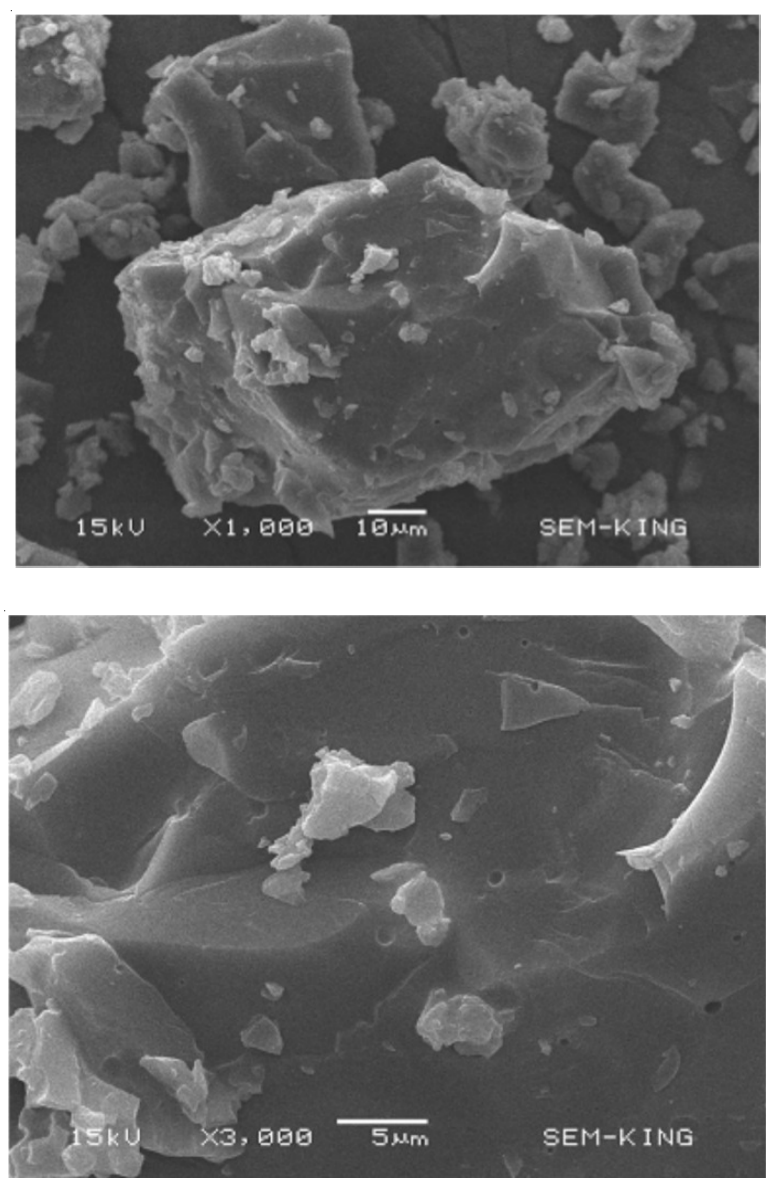

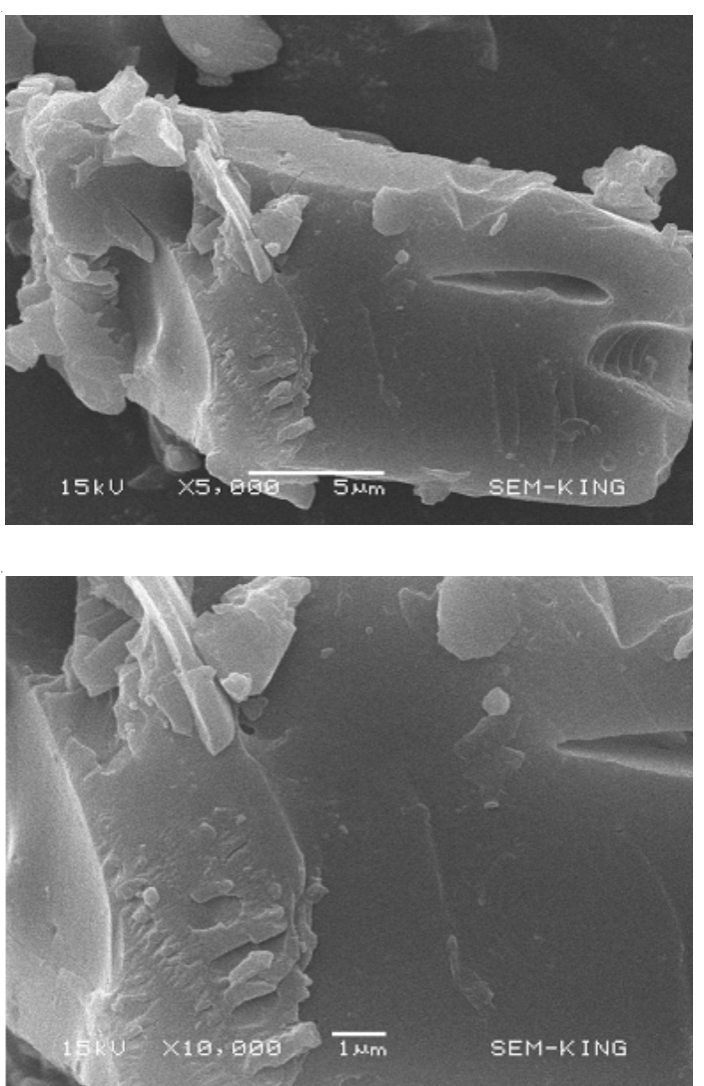

Fig. 10. SEM images of VPOSS V showing evidence of curved surface and lamellar fracture

\section{Conclusion}

Vinylphenyl oligomeric silsesquioxane based on MQ silicone resin have been directly synthesized by two steps of cohydrolysis and polycondensation. The cage and/or ladder structure of the copolymers were proved by FT-IR, ${ }^{1} \mathrm{H}$ and ${ }^{29} \mathrm{Si}$ NMR, XRD. Their molecular weights were range of $1200-$ $2300 \mathrm{~g} / \mathrm{mol}$. Thermal transitions at $\mathrm{T}_{\mathrm{g}}\left(-60 \sim 43{ }^{\circ} \mathrm{C}\right)$ and $\mathrm{T}_{\mathrm{m}}(c a$. $\left.30{ }^{\circ} \mathrm{C}\right)$ were characterized and the heat of fusion $\left(\Delta \mathrm{H}_{\mathrm{f}}\right)$ measured for crystal melting was $21.27 \mathrm{~J} / \mathrm{g}$ for VPOSS V. In addition, results indicated that the cage and/or ladder structure and the decreasing content of $\mathrm{M}$ unit mol \% in copolymers enhances the thermal properties of the VPOSSs. And the temperature with the highest thermal stablility of all VPOSSs is $401{ }^{\circ} \mathrm{C}$ of $5 \%$ decomposition in air. The curved surface and lamellar fracture observed in SEM images shows a disordered, glassy structure of the VPOSS V, which can be specialties of potential materials for connectivity and supporter of catalyst. And the most important application is that the multifunctional VPOSS can be potential moieties for temperature resistance PSA and high performance LED encapsulation LSR.

\section{ACKNOWLEDGEMENTS}

The authors gratefully acknowledged the financial support from Bureau of Academy-Locality Cooperation, Chinese Academy of Sciences (Grant No. DBNJ-2011-07), Changzhou
Science and Technology Bureau (Grant No. CE20100019) and Changzhou Yuming Electronics Co., Ltd (Jiangsu, China). Also, the authors greatly acknowledge the 29Si NMR test by Prof. Rongyong Xing of China Bluestar Chengrand Chemical Co., Ltd.

\section{REFERENCES}

1. H.W. Brandhorst, F.J. Feher, P.D. Lickiss, K. Chaloupka, C. HartmannThompson, Springer Netherlands, Vol. 3, p. 420 (2011).

2. H. Ghanbari, B.G. Cousins and A.M. Seifalian, Macromol. Rapid Commun., 32, 1032 (2011).

3. R.M. Laine and M.F. Roll, Macromolecules, 44, 1073 (2011).

4. D.B. Cordes, P.D. Lickiss and F. Rataboul, Chem. Rev., 110, 2081 (2010).

5. P.D. Lickiss and F. Rataboul, In eds.: F.H. Anthony and J.F. Mark, Advances in Organometallic Chemistry, Academic Press, Vol. 57, pp. 1-116 (2008).

6. P.R. Chinnam and S.L. Wunder, Chem. Mater., 23, 5111 (2011).

7. R.H. Baney, M. Itoh, A. Sakakibara and T. Suzuki, Chem. Rev., 95, 1409 (1995).

8. A.J. Barry, W.H. Daudt, J.J. Domicone and J.W. Gilkey, J. Am. Chem. Soc., 77, 4248 (1955).

9. E. Markovic, K. Constantopolous and J.G. Matisons, In ed.: C. HartmannThompson, Applications of Polyhedral Oligomeric Silsesquioxanes, Springer Netherlands, Vol. 3, pp. 1-46 (2011).

10. W. Huang, Y. Huang and Y.Z. Yu, J. Appl. Polym. Sci., 70, 1753 (1998).

11. L.N. Lewis, J.H. Wengrovius, T.B. Burnell and J.D. Rich, Chem. Mater., 9, 761 (1997)

12. H.W. Zhan, X.L. Lu and J. Cao, J. Polym. Eng., 17, 339 (1997).

13. G. Lai, H. Dong, X. Yang, C. Wu and J. Jiang, CN Patent 101323667 (2008).

14. W.H. Daudt, L.J. Tyler and M. Midland, US Patent 2676182 (1954).

15. T. Ganicz, T. Pakula and W.A. Stanczyk, J. Organomet. Chem., 691, 5052 (2006).

16. S.-W. Kuo and F.-C. Chang, Prog. Polym. Sci., 36, 1649 (2011).

17. C. Zhang and R.M. Laine, J. Am. Chem. Soc., 122, 6979 (2000).

18. A. Sellinger and R.M. Laine, Macromolecules, 29, 2327 (1996).

19. S. Xing and Y. Wang, In Synthesis and Application of Organosilicon. Chemical Industry Press, Beijing, pp. 811-834 (2000).

20. S.S. Choi, A.S. Lee, H.S. Lee, H.Y. Jeon, K.-Y. Baek, D.H. Choi and S.S. Hwang, J. Polym. Sci. A: Polym. Chem., 49, 5012 (2011).

21. S. Chang, T. Matsumoto, H. Matsumoto and M. Unno, Appl. Organomet. Chem., 24, 241 (2010).

22. H. Seki, T. Kajiwara, Y. Abe and T. Gunji, J. Organomet. Chem., 695, 1363 (2010).

23. E.S. Park, H.W. Ro, C.V. Nguyen, R.L. Jaffe and D.Y. Yoon, Chem. Mater., 20, 1548 (2008).

24. M.F. Roll, J.W. Kampf, Y. Kim, E. Yi and R.M. Laine, J. Am. Chem. Soc., 132, 10171 (2010).

25. D.B. Cordes and P.D. Lickiss, In ed.: C. Hartmann-Thompson, Applications of Polyhedral Oligomeric Silsesquioxanes, Springer Netherlands, Vol. 3, pp. 47-133 (2011).

26. J. Schraml, In eds.: Z. Rappoport and Y. Apeloig, In The Chemistry of Organic Silicon Compounds, John Wiley \& Sons, Ltd., Great Britain, Vol. 3, pp. 223-339 (2001).

27. G.N. Babu, S.S. Christopher and R.A. Newmark, Macromolecules, 20 , 2654 (1987).

28. W. Huang, Graduate University of Chinese Academy of Sciences (1998).

29. C.W. Lewis, J. Polym. Sci., 37, 425 (1959).

30. T.H. Thomas and T.C. Kendrick, J. Polym. Sci. A-2: Polym. Phys., 7, 537 (1969).

31. T.H. Thomas and T.C. Kendrick, J. Polym. Sci. A-2: Polym. Phys., 8, 1823 (1970).

32. Z.-X. Zhang, J.K. Hao, P. Xie, X.J. Zhang, C.C. Han and R.B. Zhang, Chem. Mater., 20, 1322 (2008). 